\title{
A Brief Replication Study Comparing Stimulants and Non-Stimulants for Attention-Deficit/Hyperactivity Disorder Treatment with a Focus on the Compliance, Efficacy, and Satisfaction
}

\author{
Hyosung Roh and Bongseog Kim \\ Department of Psychiatry, Sanggye Paik Hospital, Inje University College of Medicine, Seoul, Korea
}

\begin{abstract}
Objectives: The aim of this study was to compare the compliance, efficacy, and satisfaction associated with methylphenidate and atomoxetine for treating attention-deficit/hyperactivity disorder (ADHD).

Methods: The subjects were 44 patients who met the Diagnostic and Statistical Manual of Mental Disorder-5 diagnostic criteria for ADHD and were treated with methylphenidate or atomoxetine. The methylphenidate formulations included immediate release (IR), extended release (ER), and osmotic-controlled release oral delivery system (OROS). Patients and parents reported the average number of days per week the medication was taken. Efficacy was assessed using the ADHD Rating Scale. Satisfaction with medication scale (SAMS)-parent report form and SAMS-self-report form were used to evaluate parents' and patients' satisfaction, respectively.

Results: Patients and parents were more satisfied with methylphenidate than with atomoxetine. There were no significant differences in the compliance with and efficacy of methylphenidate and atomoxetine. Compliance with methylphenidate IR and ER was markedly lower than that with OROS methylphenidate or atomoxetine.

Conclusion: Methylphenidate OROS formulation can be considered a suitable option given its high rates of compliance, satisfaction, and efficacy.
\end{abstract}

Key Words: Methylphenidate; Atomoxetine; Compliance; Efficacy; Satisfaction.

Received: May 27, 2020 / Revision: July 21, 2020 / Accepted: September 14, 2020

Address for correspondence: Bongseog Kim, Department of Psychiatry, Sanggye Paik Hospital, Inje University College of Medicine, 1342 Dongil-ro, Nowon-gu, Seoul 01757, Korea

Tel: +82-2-950-1087, Fax: +82-2-936-8069, E-mail: kimbs328@paik.ac.kr

\section{INTRODUCTION}

Attention-deficit/hyperactivity disorder (ADHD) is a neurodevelopmental disorder that affects children, adolescents, and adults. Symptoms include carelessness, hyperactivity, and impulsivity. ADHD is diagnosed according to the following criteria established by the Diagnostic and Statistical Manual of Mental Disorder-fifth edition (DSM-5): above-threshold symptoms of carelessness or hyperactivity-impulsiveness; the presence of symptoms in more than one domain of relationships involving home, school, work, friends, or relatives; and if such symptoms interfere with, or reduce, the quality of social, academic, or professional functions [1].

The primary drugs used to treat ADHD are central nervous system (CNS) stimulants approved by the US Food and Drug Administration (FDA); from these, methylphenidate

This is an Open Access article distributed under the terms of the Creative Commons Attribution Non-Commercial License (https://creativecommons.org/licenses/by-nc/4.0) which permits unrestricted non-commercial use, distribution, and reproduction in any medium, provided the original work is properly cited.
(MPH) is the most commonly prescribed and studied drug. It is known to be effective in treating all three core ADHD symptoms: carelessness, hyperactivity, and impulsivity. The types of CNS stimulants currently available for use in South Korea are MPH immediate release (MPH IR), MPH extended release (MPH ER), and MPH osmotic-controlled release oral delivery system (MPH OROS) [2]. The common side effects of MPH OROS include decreased appetite, insomnia, headache, and nausea [3].

Atomoxetine (ATX), a selective norepinephrine reuptake blocker, is an FDA-approved non-CNS stimulant. It is also effective in reducing ADHD symptoms and is well-tolerated [4]. Atomoxetine, a non-stimulant, is preferred for patients who are at risk of drug abuse and dependence, and it can serve as an alternative for patients with tics or those who experience severe side effects of CNS stimulants such as severe insomnia or loss of appetite.

Among the existing studies that compared MPH and ATX, some studies have reported that MPH and ATX did not show 
significant differences in efficacy and tolerability [5,6]. Other studies reported that both MPH and ATX are superior to placebo in improving executive function and that the differences between the two drugs are not significant [7]. Although there were no differences observed in the efficacy and tolerability of MPH and ATX, some studies have shown that the efficacy of MPH OROS is superior to that of ATX [8-10].

In addition to efficacy and side effects, compliance and satisfaction are important factors in selecting treatment drugs for ADHD patients to improve their quality of life. Nevertheless, in previous comparative studies of drugs used for the treatment of ADHD, none involved comparisons of the drugs across various aspects, such as efficacy, compliance, and satisfaction. Investigating the compliance, efficacy, and satisfaction associate with a treatment in patients taking ADHD drugs and understanding the differences between each drug may greatly aid drug selection for ADHD patients in the future. As such, this study investigated the compliance, efficacy, and satisfaction associated with treatment in ADHD patients undergoing drug treatment.

\section{METHODS}

\section{Study subjects}

Patients diagnosed with ADHD based on the DSM-5 [1] and receiving drug treatment for at least 2 months at the Inje University Sanggye Paik Hospital were recruited between December 2019 and February 2020. Among them, patients with an existing autism spectrum disorder, intellectual disability, congenital genetic disorder, organic brain disease (epilepsy, stroke, cerebral palsy, post-concussion syndrome, etc.), or severe cognitive deficits or those who required continuous treatment due to severe physical conditions (renal failure, liver disease, cancer, hyperthyroidism, etc.) were excluded. After explaining the research purpose and methodology to the patient or caregiver, consent for participation in the study was obtained. This study was approved by the Research Ethics Review Committee of Inje University Sanggye Paik Hospital (IRB SGPAIK 2019-11-009-005).

\section{Methods}

Compliance, efficacy, and satisfaction were evaluated using a self-reported questionnaire at the time of visit of the patient and parents to the mental health clinic as outpatients.

The patients were divided into MPH and ATX groups according to the drug used for comparison between the two groups. The MPH group was further divided into MPH OROS, MPH IR, and MPH ER groups for comparison. Here, patients who were taking MPH OROS along with MHP IR or ER were included in the MPH OROS group. The dose of MPH was cal- culated by converting MPH OROS $18 \mathrm{mg}$, MPH IR $5 \mathrm{mg}$ twice a day or three times a day, and MPH ER $20 \mathrm{mg}$ into MPH 15 $\mathrm{mg}$ at equivalent doses [11].

Disease duration was defined as the period from the patients' initial diagnosis of ADHD and commencement of drug treatment at the mental health department at Inje University Sanggye Paik Hospital to the date at which the consent form and questionnaire were completed. Additionally, electronic medical records (EMRs) were reviewed to determine the presence of other diagnosed psychiatric disorders and coadministration of antidepressants and antipsychotics as well as their respective doses.

\section{Evaluation of compliance with ADHD drug treatment}

Drug compliance was evaluated using subjective and objective evaluations. A self-report questionnaire was used for subjective evaluation. The average number of days in the week on which drugs were taken over the last month was explored, with a score of 0 if no drugs were taken during the week and 7 if, on average, drugs were taken daily.

For objective evaluation, the EMRs were used to evaluate the medication possession ratio (MPR), which was calculated by dividing the number of days prescribed on the day of the outpatient visit by the number of days taken until the outpatient visit, when the consent form and questionnaire were filled out. Periods of one month or longer were included.

\section{Evaluation of the efficacy of ADHD drug treatment}

In order to evaluate the efficacy of ADHD treatment drugs, the ADHD-RS (ADHD Rating Scale, K-ARS), was used for parents [12]. It consists of 9 items suggestive of carelessness and 9 items suggestive of hyperactivity-impulsivity, with a total of 18 items. Each item is ranked by the frequency at which the child demonstrates problematic behavior, as follows: 0 denotes "rarely or never"; 1 point, "sometimes"; 2 points, "frequently"; and 3 points, "very often." A rank greater than or equal to 2 is considered abnormal for the child's developmental stage.

\section{Evaluation of satisfaction with ADHD drugs}

In order to evaluate satisfaction of parent' and patients' with ADHD drugs, the Satisfaction with Medication Scaleparent report form (SAMS-P) and the Satisfaction with Medication-self report form (SAMS-S), developed by Görtz-Dorten et al. [13] were used, respectively. The SAMS is a questionnaire that enables consistent assessment of drug satisfaction, including symptom severity, dysfunction, and quality of life using a rating scale from 1 (strongly disagree) to 6 (strongly agree), ranked by the patients and the parent, for the following 12 items: 1) behavior regulation, 2) ability to pay attention, 
3) reduced hyperactivity, 4) maintained attention and focus on tasks, 5) ability to cope with tasks, 6) forming peer relationships, 7) getting along with family, 8) getting along at school, 9) time taken to take effect, 10) duration of effects, 11) sense of well-being, and 12) overall satisfaction.

\section{Statistical methods}

The demographic data of the MPH and ATX groups were compared using an independent-sample t-test on SPSS ver. 25 (IBM Corp., Armonk, NY, USA). An independent-sample t-test was also used to compare the compliance, efficacy, and satisfaction between the MPH and ATX groups, and a Kruskal-Wallis test, a non-parametric statistical method, was performed to compare the three MPH groups (MPH OROS, MPH IR, and MPH ER) and ATX group. A Mann Whitney U-test was conducted in post hoc analysis for comparing two groups at a time. All statistical significance levels were set at $\mathrm{p}<0.05$.

\section{RESULTS}

\section{Demographic characteristics}

Of the 44 patients who participated in the study, 35 were in the MPH group and 9 were in the ATX group. The average age of the patients was $19.18 \pm 3.81$ years (range, $13-30$ years), and the average disease duration was $4.34 \pm 3.72$ years (Table 1 ).

The average ages of the MPH and ATX groups were 19.54 4.00 years and $17.78 \pm 2.68$ years, and the average disease durations were $4.40 \pm 3.93$ years and $4.11 \pm 2.98$ years, respectively. Further, 26 of the 35 patients in the MPH group were male, while 8 out of the 9 patients in the ATX group were male.

In the two groups, 31 patients in the MPH group and 7 patients in the ATX group had their intelligence quotient (IQ) test results. There was no difference between the two groups in the full-scale IQ results upon comparison and analysis.

Patients in the MPH group were taking MPH OROS 18$72 \mathrm{mg}$, MPH ER 30-60 mg, or MPH IR $2.530 \mathrm{mg}$. Some were taking a combination of MPH OROS and MPH ER or MPH IR. The ATX group received 40-100 mg doses. The average dose converted to equivalent dose was $45.79 \pm 21.99 \mathrm{mg}$ for the MPH group and $71.78 \pm 23.82 \mathrm{mg}$ for the ATX group. The average disease duration of the patients included in this study was over 4 years, and most patients had been taking a stable dose for a long period of time.

In terms of comorbidities, depressive disorder was the most common, prevalent in 24 patients, followed by anxiety disor-

Table 1. Comparison of demographic features of MPH and ATX-treated groups

\begin{tabular}{|c|c|c|c|}
\hline & $\mathrm{MPH}(\mathrm{n}=35)$ & $\operatorname{ATX}(n=9)$ & p-value \\
\hline Age $($ mean $\pm S D, y r)$ & $19.54 \pm 4.00$ & $17.78 \pm 2.68$ & 0.219 \\
\hline Duration of illness (mean $\pm S D, y r)$ & $4.40 \pm 3.93$ & $4.11 \pm 2.98$ & 0.838 \\
\hline \multicolumn{4}{|l|}{ Sex } \\
\hline Male & 26 & 8 & 0.657 \\
\hline Female & 9 & 1 & \\
\hline Full scale IQ (mean \pm SD $)$ & $94.42 \pm 15.82$ & $95.29 \pm 11.47$ & 0.892 \\
\hline Dose $($ mean $\pm S D, m g)$ & $45.79 \pm 21.99$ & $71.78 \pm 23.82$ & \\
\hline \multicolumn{4}{|l|}{ Cormorbid diagnosis (\%) } \\
\hline Depressive disorder & $21(60)$ & $3(33)$ & 0.334 \\
\hline Anxiety disorder & $2(6)$ & $3(33)$ & 0.028 \\
\hline Obsessive compulsive disorder & $2(6)$ & 0 & \\
\hline Tic disorder & 0 & $2(22)$ & \\
\hline Conduct disorder & $1(3)$ & 0 & \\
\hline Bipolar disorder & $1(3)$ & 0 & \\
\hline Schizophrenia & $1(3)$ & 0 & \\
\hline \multicolumn{4}{|l|}{ Concommitant antidepressants (\%) } \\
\hline Escitalopram (5-30 mg) & $18(51)$ & $5(56)$ & 0.879 \\
\hline Fluoxetine (20 mg) & $1(3)$ & 0 & \\
\hline Brintellix (10-20 mg) & $1(3)$ & $1(11)$ & \\
\hline Bupropion (300 mg) & $1(3)$ & 0 & \\
\hline \multicolumn{4}{|l|}{ Concommitant antipsychotics (\%) } \\
\hline Risperidone (1-5 mg) & $2(6)$ & $2(22)$ & 0.143 \\
\hline Olanzapine (20 mg) & $1(3)$ & 0 & \\
\hline Aripiprazole (5-25 mg) & $3(9)$ & $2(22)$ & \\
\hline
\end{tabular}


der, obsessive compulsive disorder, and tic disorder. There was no difference in the prevalence of depressive disorder between the MPH and ATX groups ( $\mathrm{p}=0.334)$. Among the other psychiatric drugs being taken by the patients, escitalopram was the most common antidepressant, while a combination of risperidone and aripiprazole was the most common antipsychotic medication.

\section{Comparison of the compliance, efficacy and satisfaction of the MPH and ATX group}

In the comparison of the two drug groups, subjectively reported compliance of the MPH group was, on average, 6.43 days per week and 6.89 days per week for the ATX group, with no significant difference between the two groups. However, when compliance was objectively evaluated using MPR, the compliance was higher in the ATX group $(1 \pm 0)$ than in the MPH group (0.93 \pm 0.16$)$ (Table 2 ).

The average K-ARS ADHD-RS results were 12.26 points for the MPH group and 13.00 points for the ATX group, indicating no statistically significant difference between the groups.

Table 2. Compliance, efficacy, and satisfaction between MPH and ATX treated groups

\begin{tabular}{lccc}
\hline & MPH $(n=35)$ & ATX $(n=9)$ & p-value \\
\hline Compliance-reported & $6.43 \pm 1.01$ & $6.89 \pm 0.33$ & 0.187 \\
MPR & $0.93 \pm 0.16$ & $1 \pm 0$ & 0.008 \\
ADHD-RS & $12.26 \pm 8.28$ & $13.00 \pm 8.63$ & 0.813 \\
SAMS-P & $54.29 \pm 10.48$ & $43.78 \pm 12.68$ & 0.014 \\
SAMS-S & $53.89 \pm 9.98$ & $42.33 \pm 8.11$ & 0.003
\end{tabular}

Data are presented as mean \pm SD. SD: standard deviation, MPH: methylphenidate, ATX: atomoxetine, MPR: medication possession ratio, ADHD-RS: attention deficit hyperactivity disorder Rating Scale, SAMS-P: satisfaction with medication scale-parent report form, SAMS-S: satisfaction with medication scale-self report form
The parent satisfaction measured by SAMS-P, on average, was 54.29 points in the MPH group and 43.78 points in the ATX group, while the average patient satisfaction measured by SAMS-S was 53.89 points and 42.33 points, respectively. The results indicated that both parent $(\mathrm{p}=0.014)$ and patient $(\mathrm{p}=0.003)$ satisfaction were higher in the MPH group than in the ATX group.

On comparing the individual items in the SAMS-P and SAMS-S of the MPH and ATX groups, the MPH group demonstrated higher satisfaction than the ATX group for most items, including improvement in function of daily life, satisfaction with the duration of action of the drug, and mood improvement (Table 3 and 4). There were no differences in the SAMS-P and SAMS-S results between the groups in terms of satisfaction with the aspect of the drug enabling patients to form relationships with peers and get along at school.

\section{Comparison of the MPH OROS, MPH IR, MPH ER, and ATX groups}

On comparing the MPH OROS, MPH IR, MPH ER, and ATX groups, subjectively evaluated compliance $(\mathrm{p}=0.018)$, objectively evaluated compliance $(\mathrm{p}=0.022)$, SAMS-P $(\mathrm{p}=$ $0.041)$, and SAMS-S $(\mathrm{p}=0.010)$ demonstrated differences between groups but not the K-ARS scores ( $\mathrm{p}=0.849)$ (Table 5).

The post-hoc analysis comparing two groups revealed that the MPH OROS group demonstrated higher subjective and objective compliance than the MPH IR and MPH ER groups $(\mathrm{p}=0.023, \mathrm{p}=0.034)$, where as both parents and patients in the MPH IR and MPH ER groups showed higher satisfaction than those in the ATX group ( $\mathrm{p}=0.027, \mathrm{p}=0.003$ ). Furthermore, the ATX group showed higher subjective and objective compliance $(\mathrm{p}=0.014, \mathrm{p}=0.012)$ than the MPH IR and MPH ER groups, whereas the parents and patients in

Table 3. Item statistics for parent satisfaction (SAMS-P)

\begin{tabular}{|c|c|c|c|}
\hline Item & $\mathrm{MPH}(\mathrm{n}=35)$ & $\operatorname{ATX}(n=9)$ & p-value \\
\hline 1. I am satisfied with how my child behaves while taking this medication & $4.66 \pm 1.03$ & $3.78 \pm 1.39$ & 0.039 \\
\hline 2. I am satisfied with how this medication helps my child to pay attention & $4.69 \pm 1.02$ & $3.89 \pm 1.27$ & 0.054 \\
\hline 3. I am satisfied with how this medication helps my child getting less hyperactive & $4.77 \pm 1.00$ & $3.78 \pm 1.20$ & 0.015 \\
\hline 4. I am satisfied with how this medication helps my child sustain attention and stick to tasks & $4.71 \pm 1.13$ & $3.56 \pm 0.73$ & 0.006 \\
\hline $\begin{array}{l}\text { 5. I am satisfied with how this medication helps my child cope better with homework } \\
\text { assignments and other tasks }\end{array}$ & $4.51 \pm 1.25$ & $3.44 \pm 1.01$ & 0.022 \\
\hline 6. I am satisfied with how this medication helps my child get along with other kids & $4.23 \pm 1.16$ & $3.44 \pm 1.51$ & 0.098 \\
\hline 7. I am satisfied with how this medication helps my child get along with my family & $4.57 \pm 1.20$ & $3.56 \pm 1.51$ & 0.037 \\
\hline 8. I am satisfied with how this medication helps my child to get along at school & $4.20 \pm 1.45$ & $3.89 \pm 1.17$ & 0.556 \\
\hline 9. I am satisfied with the onset of the medication's effect in the morning & $4.46 \pm 1.09$ & $3.33 \pm 1.32$ & 0.012 \\
\hline 10. I am satisfied with the duration of the medication's effect & $4.51 \pm 1.07$ & $3.56 \pm 1.51$ & 0.033 \\
\hline 11. I am satisfied with how this medication helps my child feel good & $4.29 \pm 1.02$ & $3.67 \pm 1.23$ & 0.125 \\
\hline 12. Overall, I am satisfied with the medication & $4.69 \pm 0.90$ & $3.89 \pm 1.27$ & 0.035 \\
\hline
\end{tabular}

Data are presented as mean \pm SD. SD: standard deviation, MPH: methylphenidate, ATX: atomoxetine, SAMS-P: satisfaction with medication scale-parent report form 
Table 4. Item statistics for patient satisfaction (SAMS-S)

\begin{tabular}{lccc}
\hline \multicolumn{1}{c}{ Item } & MPH $(\mathrm{n}=35)$ & ATX ( $\mathrm{n}=9)$ & $\mathrm{p}$-value \\
\hline 1. My medicine helps me reduce the trouble I have & $4.74 \pm 0.89$ & $3.89 \pm 0.93$ & 0.014 \\
2. My medicine helps me pay attention & $4.83 \pm 0.89$ & $4.00 \pm 1.00$ & 0.019 \\
3. My medicine helps me stay in my seat when I am supposed to & $4.51 \pm 1.31$ & $3.67 \pm 1.00$ & 0.079 \\
4. My medicine helps me sustain attention and stick to tasks & $4.77 \pm 1.14$ & $3.89 \pm 0.60$ & 0.004 \\
5. My medicine helps me cope better with homework assignments and other tasks & $4.63 \pm 1.14$ & $3.89 \pm 0.60$ & 0.013 \\
6. My medicine helps me get along with other kids & $4.11 \pm 1.28$ & $2.78 \pm 1.79$ & 0.061 \\
7. My medicine helps me get along with my family & $4.40 \pm 1.27$ & $3.33 \pm 1.50$ & 0.035 \\
8. My medicine helps me get along at school & $4.40 \pm 1.48$ & $3.44 \pm 1.33$ & 0.086 \\
9. The effect of my medicine start in good time in the morning & $4.57 \pm 1.04$ & $3.67 \pm 1.12$ & 0.027 \\
10. My medicine is effective long enough during the day & $4.60 \pm 1.04$ & $3.67 \pm 0.87$ & 0.017 \\
11. My medicine make me feel good & $3.69 \pm 1.28$ & $2.44 \pm 1.24$ & 0.012 \\
12. Overall, I am quite happy with my medicine & $4.63 \pm 1.11$ & $3.67 \pm 0.71$ & 0.018 \\
\hline
\end{tabular}

Data are presented as mean \pm SD. SD: standard deviation, MPH: methylphenidate, ATX: atomoxetine, SAMS-S: satisfaction with medication scale-self report form

Table 5. Compliance, efficacy, and satisfaction of OROS MPH, MPH IR/ER, and ATX treated groups

\begin{tabular}{lcccc}
\hline & OROS MPH $(\mathrm{n}=28)$ & MPH IR/ER $(\mathrm{n}=7)$ & ATX $(\mathrm{n}=9)$ & $\mathrm{p}$-value \\
\hline Compliance-reported & $6.68 \pm 0.48$ & $5.43 \pm 1.81$ & $6.89 \pm 0.33$ & 0.018 \\
MPR & $0.97 \pm 0.07$ & $0.75 \pm 0.27$ & $1 \pm 0$ & 0.022 \\
ADHD-RS & $12.71 \pm 8.69$ & $10.43 \pm 6.63$ & $13.00 \pm 8.63$ & 0.849 \\
SAMS-P & $53.64 \pm 11.32$ & $56.86 \pm 6.04$ & $43.78 \pm 12.68$ & 0.041 \\
SAMS-S & $53.79 \pm 9.34$ & $54.29 \pm 13.09$ & $42.33 \pm 8.11$ & 0.010 \\
\hline
\end{tabular}

Data are presented as mean \pm SD. SD: standard deviation, MPH: methylphenidate, ATX: atomoxetine, OROS: osmotic-controlled release oral delivery system, IR: immediate release, ER: extended release, MPR: medication possession ratio, ADHD-RS: attention deficit hyperactivity disorder Rating Scale, SAMS-P: satisfaction with medication scale-parent report form, SAMS-S: satisfaction with medication scale-self report form

the MPH IR and MPH ER groups showed higher satisfaction than those in the ATX group $(\mathrm{p}=0.023, \mathrm{p}=0.049)$.

\section{DISCUSSION}

Depressive disorder has been identified as one of the most common comorbidities of ADHD in previous research [14,15], and the prevalence of major depressive disorder in ADHD patientsis 3-75\%. Likewise, in this study, 55\% of the ADHD patients also received a diagnosis of major depressive disorder, and there was no difference observed between the two groups in this regard. It was difficult to perform a meaningful analysis involving other conditions, such as anxiety disorders, given the small sample size. As no differences were observed between the groups in terms of taking antidepressants and antipsychotics, it is unlikely that other psychiatric drugs would have affected the study results.

Although subjective compliance reported by the patients and parents were not different between the MPH and ATX groups, objective compliance was higher in the MPR group than in the ATX group. This can be attributed to reported average compliance, at 5.43 days per week, being higher than the average obtained through MPR in the MPH IR, MPH ER group was 0.75 , which indicated the drugs were being taken, on average, 5.25 days per week. Even in studies on drug treatment compliance in internal medicine [16,17], self-reported measurements of compliance were found to have lower sensitivity towards low levels of compliance than objectively evaluated compliance. Similar findings were obtained in this study, where the patients' or parents' reports of compliance were excessively high. As such, when evaluating patient drug compliance, using objective indicators as well as patient or parent reports would provide accurate data.

When comparing compliance between the four groups, the MPH IR and MPH ER groups demonstrated lower compliance with treatment than the MPH OROS and ATX groups. In a study investigating the factors affecting compliance with drug treatment in children [18], compliance was reported to be affected by a variety of factors including ADHD symptoms, comorbidities, intellectual ability of the patient, and parents' education levels in addition to the type of drug taken.

In previous studies that compared MPH OROS and MPH IR, no difference was found in the adverse effects, but one study reported that MPH OROS had greater efficacy and parent satisfaction than MPH IR [19]. Inaddition, compliance improved when patients with low compliance with MPH IR 
were given MPH OROS [20]. In a study investigating the factors affecting compliance with MPH IR [21], treatment was often discontinued in older or hyperactive children.

A previous study on ADHD compliance [22] reported that more than $40 \%$ of patients discontinued treatment after less than 6 months from the start of treatment, and only $20 \%$ of patients continued MPH treatment for more than 36 months. The patients included in this study had received drug treatment continuously throughout the duration of disease from out patient mental health services for more than 4 years on average. Thus, compared to other studies, this study may have included a high proportion of ADHD patients who continued long-term treatment for over 36 months. Therefore, the results of this study may have underestimated the difference in compliance between drugs.

There were no statistically significant differences in the K-ARS scores between the MPH and ATX groups and the MPH OROS, MPH IR, MPH ER, and ATX groups. K-ARS is designed to evaluate the patient's carelessness and hyperactivity-impulsivity according to the DSM diagnostic criteria, where a high score indicates a high severity of ADHD symptoms. Additionally, it demonstrates excellent sensitivity in evaluating the behavior of children following drug treatment, where high K-ARS scores indicate in effective control of symptoms by drug treatment [23]. In this study, MPH and ATX showed similar efficacy in relieving ADHD symptoms.

The SAMS-P and SAMS-S scores obtained in this study were significantly higher in the MPH group than in the ATX group, indicating greater drug satisfaction with $\mathrm{MPH}$ than with ATX. The formulation of MPH did not result in any differences. Patient and parent satisfaction with drug treatment is an important factor in the evaluation of overall treatment outcomes. Although the main goal of drug treatment is improvement of symptoms, the drug cannot be deemed effective unless compliance with the treatment is high. Satisfaction with drug treatment increases compliance and prevents early termination of treatment. Severity of symptoms, dysfunction, and quality of life significantly affect patient and parent satisfaction [13].

In previous research exploring the satisfaction of parents of children with ADHD using a different scale, MPH OROS group showed satisfaction for factors such as lasting drug effects until the afternoon, school life, in-class behavior, family life, and homework [24,25]. Some studies have reported improvements in quality of life and academic performance after drug treatment with MPH OROS [26]. Similar to the findings in previous research, the current study demonstrated high satisfaction with MPH for alleviation of symptoms, improvement of school and home lives, and lasting drug effects, which can be considered as advantages over ATX. There were no significant differences in satisfaction between the $\mathrm{MPH}$ and ATX groups in terms of enabling children to form better relationships with peers and get along at school. These two items received the lowest satisfaction scores. The difference between the two drugs was not large because the level of satisfaction with the role of ADHD drug treatment in forming better relationships with peers and getting along at school was lower than those of other aspects.

There are several limitations to this study. First, the study subjects were not randomized according to patient characteristics such as age and sex, and symptom severity was not evaluated prior to starting treatment. As such, the changes before and after treatment were not tracked. Second, the small number of subjects and the large variance in the number of subjects per group resulted in a limited interpretation of the results, despite correction with non-parametric statistical analysis.

Nevertheless, the strength of this study was that it simultaneously compared the compliance, efficacy, and satisfaction associate with MPH and ATX, which are the most common drugs used for ADHD treatment. Considering the relative lack of studies on patient and parent satisfaction with ADHD treatment and the fact that not only symptom severity but factors that directly influence the patients' life, such as dysfunction and quality of life, are comparable between the drugs, these aspects must be taken into account when selecting drugs for ADHD patients in the future.

\section{CONCLUSION}

Although both MPH and ATX were found to be effective in improving ADHD symptoms, greater satisfaction was observed with MPH than with ATX. Among the types of MPH, MPH OROS showed higher compliance rates than MPH IR and MPH ER. Thus, considering the scores for compliance, efficacy, and satisfaction, MPH OROS may be a better choice among the drugs for the treatment of ADHD.

\section{Acknowledgments}

This work was supported by the 2018 Inje University research grant.

\section{Conflicts of Interest}

The authors have no potential conflicts of interest to disclose.

\section{Author Contributions}

Conceptualization: Bongseog Kim. Data curation: Bongseog Kim. Formal analysis: Hyosung Roh. Funding acquisition: Bongseog Kim. Investigation: Hyosung Roh. Methodology: Bongseog Kim. Project administration: Bongseog Kim. Resources: Bongseog Kim. Software: Bongseog Kim. Supervision: Bongseog Kim. Validation: Bongseog Kim. Visualization: Hyosung Roh. Writing—original draft: Hyosung Roh. Writing—review \& editing: Bongseog Kim. 


\section{ORCID iDs}

$\begin{array}{ll}\text { Hyosung Roh } & \text { https://orcid.org/0000-0002-5116-035X } \\ \text { Bongseog Kim } & \text { https://orcid.org/0000-0002-2534-6986 }\end{array}$

\section{REFERENCES}

1) American Psychiatric Association. Diagnostic and statistical manual of mental disorders: DSM-5. 5th ed. Arlington, VA: American Psychaitric Association;2013.

2) Kim HW, Kim E, Kim JH, Park J, Bahn GH, Lee YJ, et al. The revised Korean practice parameter for the treatment of attentiondeficit hyperactivity disorder (III)-pharmacological treatment-. J Korean Acad Child Adolesc Psychiatry 2017;28:70-83.

3) Kim JS, Kim BN, Cho SC, Shin MS, Yoo HJ, Kim JW, et al. The side effects and correlates of OROS-methylphenidatein the treatment of children and adolescents with ADHD. J Korean Acad Child Adolesc Psychiatry 2010;21:63-71.

4) Kratochvil CJ, Milton DR, Vaughan BS, Greenhill LL. Acute atomoxetine treatment of younger and older children with ADHD: a meta-analysis of tolerability and efficacy. Child Adolesc Psychiatry Ment Health 2008;2:25.

5) Kratochvil CJ, Heiligenstein JH, Dittmann R, Spencer TJ, Biederman J, Wernicke J, et al. Atomoxetine and methylphenidate treatment in children with ADHD: a prospective, randomized, open-label trial. J Am Acad Child Adolesc Psychiatry 2002;41:776-784.

6) Ni HC, Lin YJ, Gau SS, Huang HC, Yang LK. An open-label, randomized trial of methylphenidate and atomoxetine treatment in adults with ADHD. J Atten Disord 2017;21:27-39.

7) Yang L, Cao Q, Shuai L, Li H, Chan RC, Wang Y. Comparative study of OROS-MPH and atomoxetine on executive function improvement in ADHD: a randomized controlled trial. Int J Neuropsychopharmacol 2012;15:15-26.

8) Newcorn JH, Kratochvil CJ, Allen AJ, Casat CD, Ruff DD, Moore RJ, et al. Atomoxetine and osmotically released methylphenidate for the treatment of attention deficit hyperactivity disorder: acute comparison and differential response. Am J Psychiatry 2008;165:721730 .

9) Yildiz O, Sismanlar SG, Memik NC, Karakaya I, Agaoglu B. Atomoxetine and methylphenidate treatment in children with ADHD: the efficacy, tolerability and effects on executive functions. Child Psychiatry Hum Dev 2011;42:257-269.

10) Hanwella R, Senanayake $M$, de Silva V. Comparative efficacy and acceptability of methylphenidate and atomoxetine in treatment of attention deficit hyperactivity disorder in children and adolescents: a meta-analysis. BMC Psychiatry 2011;11:176.

11) Kim B, Lee JS, Kim EJ, Sung HM, Shin YM, Hwang SH, et al. Treatment adherence of osmotic-controlled release oral delivery system methylphenidate in Korean children and adolescents with attention-deficit hyperactivity disorder. J Korean Acad Child Adolesc Psychiatry 2014;25:65-72.

12) Kim YS, So YK, Noh JS, Choi NK, Kim SJ, Koh YJ. Normative data on the Korean ADHD Rating Scales (K-ARS) for parents and teacher. J Korean Neuropsychiatr Assoc 2003;42:352-359.

13) Görtz-Dorten A, Breuer D, Hautmann C, Rothenberger A, Döpfner $\mathbf{M}$. What contributes to patient and parent satisfaction with med- ication in the treatment of children with ADHD? A report on the development of a new rating scale. Eur Child Adolesc Psychiatry 2011; 20 Suppl 2(Suppl 2):S297-S307.

14) Biederman J, Newcorn J, Sprich S. Comorbidity of attention deficit hyperactivity disorder with conduct, depressive, anxiety, and other disorders. Am J Psychiatry 1991;148:564-577.

15) McGough JJ, Smalley SL, McCracken JT, Yang M, Del'Homme M, Lynn DE, et al. Psychiatric comorbidity in adult attention deficit hyperactivity disorder: findings from multiplex families. Am J Psychiatry 2005;162:1621-1627.

16) Kabore L, Muntner P, Chamot E, Zinski A, Burkholder G, Mugavero MJ. Self-report measures in the assessment of antiretroviral medication adherence: comparison with medication possession ratio and HIV viral load. J Int Assoc Provid AIDS Care 2015;14:156162.

17) Wang PS, Benner JS, Glynn RJ, Winkelmayer WC, Mogun H, Avorn J. How well do patients report noncompliance with antihypertensive medications?: a comparison of self-report versus filled prescriptions. Pharmacoepidemiol Drug Saf 2004;13:11-19.

18) Kim YJ, Oh SY, Lee J, Moon SJ, Lee WH, Bahn GH. Factors affecting adherence to pharmacotherapy in childrenwith attention-deficit hyperactivity disorder: a retrospective study. J Korean Acad Child Adolesc Psychiatry 2010;21:174-181.

19) Steele M, Weiss M, Swanson J, Wang J, Prinzo RS, Binder CE. A randomized, controlled effectiveness trial of OROS-methylphenidate compared to usual care with immediate-release methylphenidate in attention deficit-hyperactivity disorder. Can J Clin Pharmacol 2006;13:e50-e62.

20) Chou WJ, Chou MC, Tzang RF, Hsu YC, Gau SS, Chen SJ, et al. Better efficacy for the osmotic release oral system methylphenidate among poor adherents to immediate-release methylphenidate in the three ADHD subtypes. Psychiatry Clin Neurosci 2009;63:167175 .

21) Atzori P, Usala T, Carucci S, Danjou F, Zuddas A. Predictive factors for persistent use and compliance of immediate-release methylphenidate: a 36-month naturalistic study. J Child Adolesc Psychopharmacol 2009;19:673-681.

22) Hong M, Lee WH, Moon DS, Lee SM, Chung US, Bahn GH. A 36 month naturalistic retrospective study of clinic-treated youth with attention-deficit/hyperactivity disorder. J Child Adolesc Psychopharmacol 2014;24:341-346.

23) So YK, Noh JS, Kim YS, Ko SG, Koh YJ. The reliability and validity of Korean parent and teacher ADHD Rating Scale. J Korean Neuropsychiatr Assoc 2002;41:283-289.

24) Kim BS, Park EJ. An observational multi-center study for evaluation of efficacy, safety and parental satisfaction of methylphenidateOROS in children with ADHD. J Korean Acad Child Adolesc Psychiatry 2005;16:279-285.

25) Song J, Kim B, Son JW, Yoo HK, Lee SI, Han DH, et al. Efficacy of OROS methylphenidate for the treatment of ADHD. J Korean Acad Child Adolesc Psychiatry 2012;23(Suppl 3):S12-S23.

26) Kim HI, Kim BN, Cho SC, Shin MS, Yoo HJ, Kim JW, et al. Change of quality of life in children with ADHD after 12 weeks OROSmethylphenidate treatment. J Korean Acad Child Adolesc Psychiatry 2012;23:103-108. 